\title{
A la mejor Minerva, Divina Madre de la sabiduría: Panegírico a la Virgen de las Nieves en la Universidad de San Marcos en 1721
}

\begin{abstract}
RESUMEN
La devoción mariana es una de las más importantes de la Cristiandad y su desarrollo y evolución se ha relacionado con diversas situaciones vividas a través de los siglos en diferentes espacios geográficos. El culto a la Virgen de las Nieves se implantó en nuestro territorio a partir del siglo Xvi y tiene gran importancia para nuestra Universidad como se comprueba en la documentación relacionada con las celebraciones que se ofrecieron en su honor. Nos interesa estudiar el sermón ofrecido en la fiesta del 5 de agosto de 1721 en la catedral de Lima y estuvo a cargo del doctor Juan de Sarricolea y Olea, profesor de Teología, quien posteriormente fue obispo de Santiago de Chile y de Cuzco
\end{abstract}

Palabras clave: Virgen de las Nieves, Sermones, Juan de Sarricolea, Universidad de San Marcos, Perú virreinal, Siglo XVIII

\section{To the best of Minerva Divine Mother of Wisdom: Panegyric to Our Lady of the Snows at the University of San Marcos in 1721}

\begin{abstract}
Marian devotion is one of the most important of Christianity and its development and evolution has been related to different situations lived through centuries in different geographical spaces. The cult of Our Lady of the Snows was established in our territory since the 16th Century, and is of great importance for our University as can be seen in the documentation referring activities offered in her honor. It's of great importance to study the sermon given at a party held at the Cathedral of Lima on August 5 , 1721 and Dr. Juan de Sarricolea, Professor of Theology was in charge, later he became Bishop in Santiago de Chile and in Cuzco.
\end{abstract}

KeYwords: Our Lady of the Snows, Sermons, Juan de Sarricolea, University of San Marcos, Viceroyalty of Peru, XVIII Century. 


\section{Introducción}

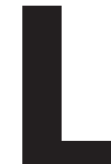

a devoción mariana es una de las más importantes de la Cristiandad y su desarrollo y evolución han estado relacionados con situaciones muy diversas, las que conocemos cada vez más gracias a las investigaciones de los especialistas en mariología. Desde los siglos iniciales de la era cristiana, han despertado cada vez mayor interés, tanto los textos bíblicos como los relatos apócrifos relacionados con la Virgen y su familia.

Inicialmente se ha privilegiado su imagen como Virgen Reina o en Majestad pero posteriormente, los temas referidos a la virginidad, la maternidad, la inmaculada concepción, la dormición y asunción de María dieron lugar a debates dogmáticos y definiciones conciliares, complementándose con numerosas representaciones artísticas o elaboraciones literarias y, especialmente, devociones y celebraciones litúrgicas que se interesaban en dar a conocer apariciones milagrosas o experiencias vividas por sus feligreses.

En general, debemos tener en cuenta las diferentes razones que han motivado, el culto mariano, ligado en primer lugar a su papel como mediadora en la salvación de la humanidad, así como a sus cualidades personales como hija, esposa y madre, modelos de comportamiento para la posteridad. A lo anterior, se han añadido las virtudes que simbolizan: pureza, modestia, valor, misericordia, fidelidad y también una condición altamente apreciada por los humanos, la belleza física, adecuándose su iconografía, tanto a los cánones existentes en las sociedades donde se representaron, como al significado que se podían dar a determinados símbolos y alegorías.

Teniendo en cuenta las referencias anteriores, podemos comprender la importancia de complementar la información procedente de diferentes fuentes, sean religiosas (bíblica, conciliar y sinodal), las obras literarias y musicales, las representaciones artísticas, así como las prácticas en su culto, variadas y numerosas en el tiempo y el espacio. Debemos tener en cuenta que el estudio de los fenómenos religiosos plantea numerosas dificultades por las características peculiares que posee es íntimo, personal y emocional pero al mismo tiempo es público, social y racional. El investigador puede verse afectado por sus creencias religiosas o ausencia de ellas pero también porque generalmente se carece de la formación necesaria de historia religiosa y sus diferentes ramas, considerando que en el caso del cristianismo pre tridentino, post tridentino y post Vaticano II no existen grandes diferencias y que el catolicismo de hoy es similar al de los primeros siglos de la Cristiandad.

En cuanto a las fuentes sumamente variadas, trataremos específicamente de la prédica, es decir, homilías y sermones que pueden ser manuscritos o impresos y presentarse individualmente o en conjunto. El estudio de la oratoria religiosa se ha visto muy favorecida por la labor de los sermonistas que han aportado una metodología de estudio muy interesante, el análisis relacionado con las 4 vías: Sermón u homilía, predicador y la sociedad de la época así como el público asistente.

Un hito importante en el estudio de la oratoria religiosa fue lo planteado en 1942 por Vargas Ugarte en su discurso sobre la oratoria sagrada en nuestro virreinato, en especial dando a conocer nombres de predicadores en su mayor parte desconocidos y a quienes debía estudiarse, como el caso del Joseph de Aguilar. Hoy día felizmente han aumentado el número de estudios con diferentes enfoques dedicados a la prédica virreinal.

Finalmente, debemos insistir que el estudio de la temática religiosa no puede realizarse aisladamente porque debe tener en cuenta que es también la historia de la conciencia colectiva, así como de la identidad de las comunidades y, por lo tanto, de sus conflictos sociales, económicos, culturales y políticos en un período determinado.

\section{El culto a la Virgen de las Nieves}

La devoción a la Virgen de las Nieves está ligada a la historia de un hecho milagroso acaecido el año 352, cuando la Virgen se apareció en sueños a una pareja de nobles cristianos, así como al Papa Liberio pidiéndoles que construyeran una Iglesia, (Imágenes I y II) sobre la parte superior del Cispio, una de las tres cimas de la colina del monte Esquilino, en el mismo lugar donde al día siguiente encontrarían nieve fresca. En la mañana del 5 de agosto, en pleno calor del verano, la colina del Esquilino apareció cubierta de nieve y además la tradición afirmaba que, el perfil de la Iglesia estaba físicamente dibujado en el suelo. 
El Papa Liberio encargó la construcción de la Basílica Liberiana, hacia el ańo 360 y está dedicada a la Virgen María, bajo el título de 'Nuestra Señora de las Nieves (Imagen III), siendo una de las cuatro basílicas patriarcales de Roma y la única que ha conservado su estructura paleocristiana. Bajo el pontificado de Sixto III se inició su restauración (432 al 440 d.C.), honrando la proclamación de María como madre de Dios (Theotokos) en el Concilio de Éfeso (431 d.C.) y debido a su milagroso origen se la designó con el nombre de Santa María la Mayor. Asimismo, el pontífice encargó la construcción en la basílica de una «cueva de la Natividad» similar a la de Belén y se la decoró posteriormente con ricos mosaicos mostrando el milagro de la nieve, así como escenas bíblicas (Imagen IV).

El culto a esta advocación ha adquirido suma importancia en las Islas Canarias, especialmente en la Isla de la Palma donde es su patrona. La imagen venerada en el Santuario llegó probablemente a fines de la Edad Media, como resultado de un naufragio o introducida por misioneros mallorquines que buscaban evangelizar a los pobladores aborígenes. Si bien relatos legendarios mencionan a monjes irlandeses o marinos mediterráneos, quienes estuvieron siglos antes de la conquista de las Islas Canarias. Son importantes dos documentos, la Bula del Papa Martín $\mathrm{V}$ del 20 de noviembre de 1423 indicando la existencia de una iglesia dedicada a dicha imagen bajo la advocación de Beatae Mariae de La Palma, así como una Data del Adelantado Don Alonso Fernández de Lugo, fechado eñ 23 de enero de 1507 mencionando el nombre de "Santa María de las Nieves» y la donación de solares a la Virgen donde se edificó el templo primitivo y que tuvo su forma final recién en 1646.

La imagen de la Virgen está hecha en terracota policromada y tiene una altura de $57 \mathrm{~cm}$ (Imagen V). Posiblemente fue realizada a fines del siglo XIV lo que explicaría su relación con los estilos artísticos de la época (románico tardío o inicios del gótico). Está vestida suntuosamente con un manto azul sobre sus hombros, traje color rojo, toca blanca en la cabeza; las orlas y el cinto son dorados, como los del Niño Jesús y se encuentra en un altar-trono de plata repujada. Lleva joyas muy ricas, recibidas a través de los siglos, incluso algunas procedentes del Nuevo Mundo. Ese Real Santuario, título que posee desde 1649 cuando Felipe IV lo acogió en su Real Patronato, guarda en su tesoro objetos muy valiosos como tallas flamencas, ofrendas o votos de sus fieles, óleos marianos y retablos, entre otros.

Los azares climáticos frecuentes en el siglo XVII afectaron a la isla, causando enormes pérdidas en la agricultura y ganadería en la región y se inició la costumbre de romerías al santuario que se han proyectado en celebraciones lustrales si bien las fiestas más importantes tienen lugar el 5 de agosto. En estas fiestas se traslada la imagen de la Virgen desde su santuario hasta la ciudad ubicada en la costa. Alrededor de este acontecimiento religioso tienen lugar multitud de actos populares de alabanza a su patrona como danzas, obras teatrales, diálogos entre naves y castillos entre otros.

\section{Implantación de las devociones marianas en el Mundo americano}

\section{a) La etapa inicial}

El proceso de evangelización del Nuevo Mundo, especialmente en el período que comprende el siglo XVI y parte importante del siglo XVII, se dio en condiciones muy diferentes a otros procesos de cristianización llevados a cabo por la Iglesia Católica, como ya hemos explicado (Flórez, 1999).y que habían permitido la existencia de un "cristianismo folclórico" en el mundo medieval, debido a una serie de circunstancias como por ejemplo. el hecho de no estar claramente cohesionada la organización eclesiástica, las características mentales de sus miembros, así como la falta de fijación de la ortodoxia y ortopraxis católicas durante la Alta Edad Media.

En el caso americano, debemos tener en cuenta que el proceso de catequesis y aculturación se realiza en situaciones verdaderamente diferentes a los que se habían dado en siglos anteriores. En primer lugar, los cambios en cuanto los enfrentamientos bélicos por diferencias en cuanto al armamento y tácticas empleadas en la "guerra moderna». Igualmente la necesidad de completar la conquista militar con el control mental e ideológico de los vencidos, siendo necesarios mecanismos adecuados para la catequesis y aculturación como la prédica, las festividades entre otros.

A lo antes mencionado, debemos ańadir la importancia que han tenido en el siglo xvI las Reformas 
religiosas, protestante y católica, esta última apoyada principalmente en las disposiciones del Concilio de Trento. Esos cánones hicieron tomar conciencia a los obispos de la importancia del ministerio de la palabra, es decir, una prédica que formara y controlara, privilegiando determinados cultos como el mariano, así como otras prácticas devotas. Nuestro territorio se vio además afectado por las medidas dispuestas por el Tercer Concilio Limense desde fines del siglo Xvi y esa pastoral post tridentina buscó dar mayor seguridad a los fieles frente a los peligros materiales e incluso inseguridades en cuanto al Más Allá. Es en este ámbito que el culto mariano desempeńa un papel preponderante, advocaciones (Virgen de los Mareantes, Rosario entre otras), procesiones, escapularios, oraciones, cofradías son solamente algunas manifestaciones en lo religioso, a las que podemos añadir las expresiones en lo artístico, literario o folclórico.

En el virreinato peruano, las prácticas devotas a la Virgen de las Nieves se iniciaron poco tiempo después de la conquista española, si bien tenemos poca información a excepción de la difusión a poblados próximos como Mallay y Oyón, a la región de Ancash (Sihuas), la región minera de Pasco en los Andes centrales y a zonas costeras del departamento de Ica, así como en fue la ciudad de Tinta en la región de Cuzco. .El culto también se extendió a Chile en la época del enfrentamiento entre los conquistadores con los naturales del lugar, protegiéndolos y obrando milagros la imagen que se conserva actualmente en la ciudad de Concepción y que había sido enviada por Carlos v al obispo del lugar Antonio de San Miguel (OFM).

Sin embargo, el mayor auge a esta devoción en el período colonial se dio en Villa Rica de Oropesa (actual Huancavelica) por haberse realizado su fundación el 5 de agosto de 1571, festividad de la Virgen, tal como lo narra con detalles los Anales de Montesinos (Vargas Ugarte (1956). Posteriormente, esta advocación adquirió preponderancia en la ciudad de Coracora, antigua capital de la provincia de Parinacochas y se mantiene hasta hoy día. Conocemos relativamente poco de sus orígenes en esta región, salvo los datos que se señalan provenientes de tradiciones, similares a los de otras advocaciones marianas: visiones, sueńos o apariciones, así como el milagro de una imagen que rehúsa continuar una trayecto- ria establecida o aparece luego de un naufragio. En Coracora se seńala que en el siglo XvıII, la imagen procedente de España y transportada al Cuzco, debió detenerse por una tormenta de nieve, siendo imposible continuar el viaje. Sin embargo, otra tradición ofrece una versión diferente mencionando a un niño indígena que pastoreaba y la aparición en un nevado de la Virgen con el nińo, trasladada a la iglesia principal y fomento a la piedad popular, acrecentado por la tradición del apoyo mariano durante la guerra de la Independencia.

\section{b) La Universidad de San Marcos y el culto mariano $^{1}$}

Nuestra institución ha integrado a sus actividades académicas la celebración de fiestas - cívicas, religiosas e institucionales - destacando las de su patrono San Marcos, así como las de San Bernardo y los doctores de la Iglesia. Tenían gran importancia las festividades marianas, especialmente la de Nuestra Señora de la Antigua (Imagen VI), la virgen de las Nieves y también la de Inmaculada Concepción. La Universidad se hizo cargo del culto y los gastos de la capilla de Nuestra Seńora de la Antigua y la sustentación de grados académicos tenía lugar en su capilla de la catedral, donde estaba la copia de la imagen de la Antigua de Sevilla, que mandó hacer el Arcediano de Sevilla, don Juan Federegui. Su culto se incentivó en las primeras décadas del siglo XVII, si bien los sismos en la capital afectaron su capilla que debió ser reparada y que pudieran tener lugar actividades como la misa con sermón en diferentes ocasiones como la elección del Rector, con asistencia del Claustro y del Cabildo Metropolitano, la Misa de Aguinaldos por la Universidad, que abonaba el gasto del importe de los derechos de grados y también se celebraba allí la fiesta de nuestra Señora de las Nieves, y la fiesta y su participación en el octavario de la Inmaculada los primeros días de diciembre, y por cédula de 1670 tuvo a su cargo festejar el sexto día. Esos días celebraban misas solemnes, a las que podía asistir el virrey, siendo los profesores, especialmente los doctores en Teología quienes se encargaban de pronunciar los

1 La información proviene de las obras de Luis A. Eguiguren y Antonio de la Calancha 
sermones y los miembros del claustro universitario debían participar en esas fiestas.

\section{La celebración de la fiesta de la Virgen de las Nieves en 1721}

\section{a) Características de la prédica}

Hemos definido en anteriores trabajos al sermón como el discurso oral pronunciado por un predicador en el púlpito de manera solemne. Se ha elaborado de acuerdo a las normas de la oratoria y la retórica, empleando, por lo general, un texto sagrado para explicar tópicos que ayuden a educar a los fieles, puesto que sus funciones fundamentales son la ortodoxia y la ortopraxis, es decir, asuntos de la fe y la moral. Además del término sermón, el más difundido, puede denominarse panegírico, oración y discurso y en su tipología existen los ordinarios o De tempore, los dedicados a santos, los denominados Ad Status, los memoriales o de difuntos y los que son materia de este trabajo, los marianos que se pronuncian en las festividades dedicadas a episodios de la vida de la Virgen o a sus diversas advocaciones.

Los sermones han evolucionado a través de los siglos, especialmente con las modificaciones de la pastoral católica desde fines de la Edad Media, tanto en lo concerniente a la prédica como a la práctica sacramentaria. La preparación de los sermones debía tener en cuenta los aspectos ligados al contenido que debe ser fiel a la doctrina, mientras que en la forma debía comenzar por Dios y terminar por Él pero haciendo buen uso del lenguaje, tal como señalaba San Agustín en De Doctrina cristiana. La retórica era importante en las etapas del trabajo, la inventio o conceptualización, seleccionando los materiales y las fuentes que cimentaban un magisterio apoyado en la tradición. Esa tarea necesitaba tiempo y no bastaba la cantidad de libros consultados sino que se debía elegir con buen juicio lo mejor, evitando todo lo que pudiera afectar la recta interpretación de los textos, aplicando argumentos sólidos de acuerdo al público y la ocasión. A continuación, se realizaba la disposición o arreglo de las partes de acuerdo al material seleccionado. Finalmente, tendría lugar la elocución, es decir, la entrega o expresión del trabajo realizado que podía variar en el caso de realizarse la edición impresa.
Desde sus inicios las universidades medievales habían enfatizado acerca de los estrechos lazos entre enseñanza y prédica, así en el siglo XIII se señalaban los tres requerimientos de un maestro en teología: leer, disputar y predicar. Más tarde se formalizaron en los estatutos las prácticas de esos ejercicios académicos, reflejando dos tipos de prédica, los sermones oficiales los domingos y feriados, mientras que el segundo sentido, se refería al ejercicio académico en la facultad de teología. Los estatutos de la Universidad incluían numerosas referencias a la importancia de predicar Magísteres y estudiantes de teología se esperaban que asistieran a los sermones en la universidad, mientras que los alumnos de las escuelas de Artes y Gramática asistían con sus maestros a escuchar sermones como complemento de su enseńanza (Roberts 1998). Es interesante para el caso de San Marcos señalar que "los estatutos de la Universidad de Salamanca incluía en los estatutos de 1411 provisiones para la prédica regular de sermones universitarios» (Id. p. 327). Tal como lo seńalaban los estatutos de la Universidad de Bolonia de 1364 .

\section{b) El predicador}

Consideramos que es fundamental conocer la formación intelectual y personal recibida por el predicador en sus centros de formación académica y religiosa, lo que permitiría explicar tanto el contenido como el estilo del sermón, los instrumentos de trabajo utilizados para elaborar la prédica, complementándolos con la ayuda proveniente de las bibliotecas conventuales como los tratados de prédica y los sermonarios.

Durante la Edad Media se hicieron presentes los Ars praedicandi (Briscoe 1992), ofreciendo a los interesados métodos seguros para elaborar un buen sermón, teniendo en cuenta los amplios objetivos de la prédica. A partir del siglo Xvi, circularon los Sermonarios impresos o colecciones de sermones de un determinado predicador, aprobados por la autoridad eclesiástica y en algunos casos, precedidos por una introducción con los consejos para su elaboración. Se les reconoce actualmente su gran valor histórico porque es una fuente de estudio para el conocimiento de la oratoria religiosa y la práctica de la prédica, convirtiéndose en un útil primario para la educación y el cuidado de los fieles. 
Debemos preocuparnos por el mensaje que ha querido transmitir el predicador, tanto a nivel de creencias o de normas y en nuestro caso lo que nos transmite del mundo académico y sus relaciones con lo religioso. Es sumamente importante situar al sermón en el ámbito en que tuvo lugar: la sociedad en la que se elaboró y predicó pero también el público asistente para comprender mejor sus funciones. Asimismo, necesitamos insistir en el valor que tiene este discurso religioso en una sociedad donde la oralidad es fundamental en lo cultural, especialmente si quien lo pronuncia está calificado para ello (Sánchez: 2000, 761) y, sobre todo, si la prédica tiene lugar en una ceremonia pública.

En cuanto al predicador Juan de Sarricolea ${ }^{2}$ sabemos que nació el 6 de diciembre de 1670 en Huánuco, hijo de Diego de Sarricolea Zamudio y María de Olea de Aguinaga, de importantes familias limeñas, destacados por los servicios prestados a la Corona española. En lo personal, poseía una inteligencia sobresaliente y desde muy temprana edad estudió gramática y retórica en Lima y posteriormente estudió en la Universidad de San Marcos, graduándose de doctor en Teología. Habiéndose ordenado como sacerdote fue nombrado párroco de los curatos de San Pedro de Carta y Santiago de Maray, desarrollando una importante labor con su feligresía, mayoritariamente indígenas.

En el año 1698 obtuvo mediante oposición la Cátedra de Artes en su Alma Mater, desempeñando a partir de 1721 las Cátedras de Nona y de Prima de Sagrada Teología. Tuvo además los cargos de Examinador sinodal del arzobispado de Lima, Calificador del Santo Oficio y logró también ser elegido como Canónigo penitenciario de la Catedral de Lima³. El 19 de setiembre de 1723 fue nominado obispo de Córdoba (Tucumán, Argentina) por el papa Inocencio XIII y confirmado el 22 de noviembre del mismo año. El 8 de octubre del año siguiente fue ordenado obispo por Diego Morcillo Rubio de Auñón, arzobispo de Lima. Aprovechando el viaje a su diócesis, visita que inició por Jujuy y culminó

2 Escogimos el nombre de Juan tal como se indica en el sermón y en los documentos de la Universidad, a diferencia de otras informaciones que se refieren a él como José.

3 Sacerdote del cabildo catedralicio nombrado por el obispo y a quien se le conceden ciertas atribuciones en asuntos relacionados con el sacramento de la penitencia. Se designa generalmente a quien destaca por su capacidad en lo doctrinal e integridad en su vida personal. cuando, después de recorrer seiscientas leguas de su obispado, llegó a Córdoba. El 20 de abril de 1729 en una carta al monarca realizó observaciones precisas sobre la administración de justicia en su región. Proponía que se creara ese año una escuela de derecho en Córdoba y al igual que otras autoridades, solicitaba se creara una audiencia ese lugar (Vivas 2012).

Nombrado por Clemente XII obispo de Santiago de Chile el 24 de julio de 1730 se instaló en dicha ciudad en abril de 1732 luego de hacer la visita pastoral a la región de Cuyo. Uno de los graves problemas que tuvo en su diócesis fue el ocasionado por el terremoto de 8 de julio de 1730 y que afectó gravemente la ciudad, lo que determinó buena parte de su actuación en el poco tiempo que estuvo al frente de esta diócesis. Estableció una casa de recogidas con sus constituciones, se ocupó de la reconstrucción de la catedral y de la Iglesia de Santa Ana, contribuyendo con sus fondos personales. Fue, además, nombrado virrey en ínterin del Perú para aquellas situaciones de excepción en que el virreinato quedara sin su cabe$\mathrm{za}$, nombramiento que no fue necesario que ocupara. (Imagen VII).

Fue elegido obispo de Cusco el 18 de febrero de 1734, siendo confirmado el 5 de mayo del mismo año e ingresó a la antigua capital del Tahuantinsuyo el 11 de febrero de 1736 donde permaneció durante cuatro ańos y entre los hechos destacados tenemos la detenida visita que hizo a su enorme diócesis así como el decreto de 1739 que se fundara en la doctrina de Huayllabamba una escuela y que: «los [varoncitos] q fueren abiles, y tubiesen competente vos se entreguen a algun cantor Mr de Capilla para q les enseñe el Canto y la solfa y nunca falte con esto quien pueda oficiar siquiera una misa» (Baker 2003:185). Falleció el 2 de diciembre de 1740 en Cuzco.

Entre sus obras tenemos:

1) Teses ex tertia Divi Thomae parte. Defenduntur mane ad Regala D. Martin Colegium. Vespere ad Maximum D. Pauli a B.D. Ioanne de Sarricolea \&Olea, Martiniani Athenaei balumno pururatio. Dic. 13 mensis nouembris anni 1693 (inédito).

2) Alegación del Lic. D. Ivan de Sarricolea y Olea. Colegial del Real de S. Martín. En la oposición a la Cátedra de Artes a 2 de octubre de 1695 (inédito).

3) Oración panegírica a la Minerva de las Ciencias, la Sabiduría de las escuelas, María Santísima en la 
gloriosa dedicación de sus Nieves, Dixola el día V de Agosto de 1721 el Doct. D. Juan de Sarricolea y Olea. Catedrático, entonces de nona y oy de prima de Sagrada Teología. Lima.

Como información complementaria, debemos indicar que uno de sus hermanos, Martín, quien realizó estudios en el Colegio San Martín, ingresó también a la carrera eclesiástica, siendo ordenado sacerdote, desempenándose como Canónigo magistral de la Iglesia de Charcas, y por bula de Clemente XI dirigida a Felipe V rey de España comunicando su nombramiento como coadjutor del obispado del Paraguay. Asimismo, fue nombrado titular del obispado de Calydon (Grecia) pero no llegó a asumir ambos cargos. Respecto a la fecha de su fallecimiento hay discrepancias porque se señalan los años $1720 \mathrm{y}$ 1723.

\section{c) Oración Panegírica a la Minerva de las Ciencias, la Sabiduría de las Escuelas, María Santísima en la gloriosa dedicación de sus Nieves}

Se ofreció el 5 de agosto de 1721. Fiesta de Nuestra Señora de las Nieves, Patrona de la Real Universidad de San Marcos, en la capilla de Nuestra Señora de la Antigua en la Santa Iglesia Metropolitana de los Reyes. Asimismo, se explica que fue con ocasión de estrenarse un magnífico Tabernáculo erigido y consagrado a esa imagen por su Rector ${ }^{4}$, el doctor Pedro de la Peńa y Cívico, Consultor, y Juez Ordinario del Santo Oficio, Catedrático de Prima de Sagrados Cánones, y Arcediano de dicha Iglesia. El sermón estuvo a cargo del Doctor Juan de Sarricolea y Olea, Catedrático, entonces de Nona, y actual de Prima de Sagrada Teología, de esa misma Universidad, Cura Rector de la Catedral, y Examinador Sinodal del Arzobispado- quien lo dedicó al Rector y al Claustro Universitario y la impresión estuvo a cargo de Ignacio de Luna en la Imprenta Antuerpiana en Lima (Imagen VIII).

El texto consta de 92 folios, divididos en Salutación (ff. 1 a 16) y el Sermón propiamente dicho (17 a 51). En cuanto a los folios restantes corresponden a los siguientes textos:

$4 \quad$ Elegido por cuarta vez.
- Dedicatoria al Rector Pedro de la Peña y Cívico, nacido en Lima en 1646 y con estudios en el Colegio San Martín y la Universidad de San Marcos, donde fue Profesor en las cátedras de Código (1688), Vísperas de Sagrados Cánones (1690) y Prima de Sagrados Cánones (1705). Fue elegido Rector en 1718, cargo que ejerció durante 4 años.

- Aprobación del Alonso Messía, jesuita, Doctor en teología, quien había sido Provincial de su Orden y Calificador del Santo Oficio, así como uno de los más destacados predicadores de la época. Fechada el 25 de agosto de 1721,

- Censura del P. Juan de Gazitua, O.P. Calificador del Santo Oficio, catedrático de San Marcos y Prior del Convento del Rosario, entre otros cargos. Fechada el 27 de septiembre del mismo año.

- Licencia del Provisor Real D. Bartolomé de Carrión y Villasanta del $1^{\circ}$ de octubre siguiente.

El tema o cita bíblica empleado en la prédica fue: Extollens Vocem quaedam Mulier de turba dixit illi: Beatus Venter, qui te portavit, \&Ubera, qua suxistis. Pertenece al Evangelio de Lucas, c. 11, v. 27 [Una mujer de la multitud alzó la voz y dijo. ¡Dichoso el vientre que te llevó y los pechos que te criaron!] y se utilizaba frecuentemente en los sermones marianos. Ha sido impreso a página completa porque generalmente se hacía a dos columnas.

Las citas se colocaron al costado del texto y sumamente abreviadas, lo que no siempre facilita la identificación del autor o de la obra citados. No obstante, las referencias que proporciona comprueban su interés por los estudios bíblicos y el manejo que demuestra de autores expertos en esos temas como Cornelio Alapide, Gaspar Sánchez, Paulo. Sherlock, Benito Arias Montano, incluso autores judíos como Flavio Josefo o el Rabino Shlomo Yitzjaki Asimismo, encontramos interés por autores clásicos (poetas, historiadores y científicos) y algunos humanistas como Carlo Sigonio, Piero Valeriano Bolzani y Filippo Beroaldo a diferencia de otros predicadores de la épo$\mathrm{ca}$, no muestra mayor interés por autores medievales, a excepción de Beda el Venerable, algunos Padres de la Iglesia, Antonino de Florencio, Juan Gerson y Nicolás de Lira. Es de gran interés la referencia a Diego de León Pinelo y su Hypomnema apologeticum pro Regali Academia Limensi, importante alegato en 
defensa de la Universidad de San Marcos frente a las opiniones desfavorables acerca de la cultura americana de Justo Lipsio.

Teniendo en cuenta que el Panegírico tiene lugar en una fiesta mariana relacionada además con la Universidad, interesa conocer los términos así como los símbolos marianos utilizados por el predicador. En primer lugar, aquellos relacionados con el mundo clásico, como son Minerva, Pallas, Argos, Júpiter, las bíblicas que son más conocidas como Ara, Altar, Tabernáculo, Trono de sabiduría, sin olvidar as que se refieren a la naturaleza: palma, abeja, vara, fuente y nube. Luego, nos interesan todas aquellas que manifiestan su relación con el saber intelectual como es el caso de Madre de la sabiduría, Presidenta de las escuelas, sabia y sabiduría, incluso aquellos nombres que tienen en cuenta su papel vigilante como son centinela y atalaya.

En lo concerniente a la Universidad Pontificia, Sarricolea emplea aquellos términos que ensalzan su papel destacado en la vida intelectual de la época y la denomina Atenas Peruana, Docto Museo, Regia Academia, Casa o también Alcázar de la sabiduría, Huerto de doctores, Jardín de doctrinas o de las ciencias. Tengamos presente que el público asistente pertenece a lo que los sermonistas denominan litterati, es decir, intelectuales, con habilidades cognitivas diferentes a quienes carecían de preparación académica.

Sería interesante hacer un estudio más detallado de la visión que tiene este profesor, no solamente de su institución y sus miembros sino también de la vida intelectual de la época, lo que presentamos se relaciona especialmente con un aspecto del desarrollo académico de nuestra institución y como hemos comprobado en otros casos, nuestros predicadores no manifiestan las deficiencias que señalan algunos estudios tradicionales sobre el período colonial, incluso habría sido sumamente útil que en la Colección del Pensamiento Educativo Peruano, el tomo dedicado a los siglos XVII y XVIII se hubiera prestado mayor atención a la oratoria sagrada, tanto en el estudio introductorio como en la antología de textos.

Revisando el texto de Sarricolea y teniendo en cuenta otras informaciones, sería interesante saber ¿cuáles fueron los sermonarios peninsulares que tuvo a su alcance. Guibovich (2000) menciona que el obispo donó al Colegio de los jesuitas del Cuzco la Commentaria moralia in evangeliam historiam de Diego Baeza, Valladolid: 1629, pudo quizás conocer otros sermones de ese predicador dedicados a la Virgen de las Nieves y que fueron publicados en 1649, o incluso otros sermonarios de autores jesuitas o dominicos dedicados a la misma advocación.

\section{Conclusiones}

a) El culto a la Virgen de las Nieves ha sido importante en el mundo europeo occidental desde la Antigüedad Tardía hasta la actualidad.

b) En el caso peruano ese culto jugó papel destacado en el período colonial y contó con importantes apoyos, tanto eclesiásticos como civiles, especialmente en ciertas regiones andinas.

c) La Universidad de San Marcos ofreció importantes fiestas en honor de la Virgen de las Nieves en los siglos XVII y XVIII con misas solemnes y sermones a cargo de destacados profesores de Teología

d) El Panegírico analizado nos ofrece valiosas informaciones en temas religiosos y académicos pero plantea una serie de interrogantes acerca de la relación existente entre las advocaciones de las Nieves y la Antigua. 


\section{Bibliografía}

\section{Fuentes editadas}

Constituciones y Ordenanzas [...] de la Real Universidad y Estudio General de San Marcos (1735). Lima: Imprenta Real.

Echave y Assu, Francisco de (1688). La Estrella de Lima convertida en Sol sobre sus tres corona. Juan Bautista Verdussen, Amberes, en http://www.google.com

Sarricolea y Olea, Juan (1721). Oración Panegírica a la Minerva de las Ciencias, la Sabiduría de las Escuelas, María Santísima en la gloriosa dedicación de sus Nieves. Lima: Imprenta Antuerpiana, en http://www.archive.org

\section{Bibliografía}

BAKer, Geoffrey (2003). "La vida musical de las doctrinas de indios del obispado del Cuzco", en Revista Andina No 37: 181-205, segundo semestre, CBC, Cusco.

Delumeau, Jean (1997). "Mentalidades religiosas en el Occidente Moderno", en Lienzo, $\mathrm{N}^{\circ}$ 18: 265.283, Universidad de Lima, Lima.

Eguiguren, Luis Antonio (1940). Diccionario Histórico Cronológico de la Real y Pontificia Universidad de San Marcos y sus Colegios. Crónica e investigación. Tomo I. Lima: Librería e Imprenta Gil.

Eguiguren, Luis Antonio (1949). Diccionario Histórico Cronológico de la Real y Pontificia Universidad de San Marcos y sus Colegios. Tomo II. Lima: Imprenta Torres Aguirre.

Eguiguren, Luis Antonio (1951). Diccionario Histórico Cronológico de la Real y Pontificia Universidad de San Marcos y sus Colegios. Tomo III. Lima: Imprenta Torres Aguirre.

Flores, Stefano y Salvatore MEO (2001). Nuevo Diccionario de Mariología. Madrid: Ediciones San Pablo.

Flórez, Gloria Cristina (1999). «El poder de la palabra: Evolución de la prédica católica», en Scientia et Praxis, $N^{\circ}$ 22-23; 23-40, Universidad de Lima, Lima.

FLórez, Gloria Cristina (2012). «La herencia del medioevo en el Perú de los Austrias: Instituciones y ceremonias», en Anuario Jurídico y Económico Escurialense), Vol. XLV: 559-580, San Lorenzo del Escorial, España.
Flórez, Gloria Cristina (2017). «La Virgen de las Nieves en el Perú: pasado y presente», Manuel Poggio y Víctor Hernández, Actas del I Congreso Internacional de la Bajada de la Virgen: 117-128. La Palma de Gran Canaria: Cartas Diferentes Ediciones.

Flórez, Gloria Cristina (2018). "Historia de la Real y Pontificia Universidad de San Marcos de Lima en las obras de Calancha, León Pinelo y Baquíjano. Tres intelectuales sanmarquinos», en Anuario Jurídico y Económico Escurialense, Vol. 52 (2019) 417-440, San Lorenzo del Escorial, España.

Glave, Luis Miguel (2013). Entre la sumisión y la libertad, Siglos XVII-XVIII. Colección Pensamiento Educativo Peruano. Lima: Derrama Magisterial.

Guarda, Gabriel O.S.B. (2016). La Edad Media de Chile Historia de la Iglesia Desde la fundación de Santiago a la incorporación de Chiloé 1541-1826. Santiago de Chile: Universidad Católica de Chile.

Guibovich Pérez, Pedro (2000). «Libros antiguos en la Universidad del Cuzco: la «Biblioteca de los Jesuítas», en Histórica: XXIV.1: 171-181. Lima: PUCP.

León Pinelo, Diego de (1949). Semblanza de la Universidad de San Marcos. Lima: Talleres Scheuch.

Ramos Domingo, José (1997). Retórica-Sermón-Imagen. Salamanca: Universidad Pontificia de Salamanca.

Roberts, Phyllis B. (1998). «Medieval University Preaching: The Evidence in Statutes», Jacqueline Hamesse y otros. Medieval Sermons and Society: Cloister, City, University, 317-328. Belgique: Fédération Internationale des Instituts d'Etudes Médiévales, Louvain-la-Neuve.

SÁnchez, Manuel Ambrosio (2000). «Vernacular Preaching in Spanish, Portuguese and Catalan» Beverly M. Kienzle. The Sermon. Belgique: Brépols, Turnhout.

Vargas Ugarte, Rubén. S.J. (1956). Historia del culto a María en Iberoamérica y de sus imágenes y santuarios más celebrados. 2 tomos. Madrid: Talleres Gráficos Jura.

VArgas UGarte, Rubén. S.J. (1942). La elocuencia sagrada en el Perú de los siglos XVII y XVIII. Lima: Gil S. A, Impresores.

Vivas, Mario Carlos (2012), «Intentos para la creación de una Real Audiencia en Córdoba del Tucumán», en Cuadernos de Historia N» 22: 77-108. Córdoba: Instituto de Historia del Derecho y de las Ideas Políticas Roberto I. Peña. 


\section{Anexos}

Documentales

\section{Anexo I}

47.-Este servicio y Tributo a la Santísima Virgen se decretó por el claustro en seis de setiembre de 1630 admitióse el mismo día por el señor arzobispo Don Fernando Arias de Vgarte doctor desta Vniuersidad y criollo de este Reyno con gran aplauso de su cavildo y confirmolo el Señor conde de chinchón en treinta de setiembre del mismo año y fueron las condiciones de ambos gremios que se continuase en aquella nave el dar los grados maiores y selebrar en aquel altar la fiesta de la Virgen a cinco de agosto que es la fiesta de nuestra señora de las nieves dando cinquenta pesos a los prevendados y canonigos que an de asistir y oficiar la missa-y á dispossición de dos comisarios el uno nombrado por la Vniuersidad y el otro por el cavildo, se gaste lo necesario para la musica, sera y olores, con toda solemnidad y lo que sobrase de lo caido de las propinas lo aplicasen para comprar los adornos que al claustro le pareciere de mas culto y grandeca a lo festivo del altar y nabe con calidad que en las fiestas que hiciere la Vniuersidad se traigan para el adorno de su capilla, dispusose que los doctores y maestros con capirotes y borlas sus Vedeles con masas su secretario, contador, alguacil se juntasen el día de la fiesta en la antesala del cavildo y desde allí saliesen a selebrar la fiesta. Ofresió el Señor arcobispo como consta del decreto referido cantar aquel día y todos los que se hallase en la ciudad la missa de Pontifical todo lo demas se executa y solo este onor se escusa.

Calancha, Antonio (osa). "Historia de la Universidad de San Marcos». En: Eguiguren, Luis Antonio. Diccionario histórico y cronológico de la Real y Pontificia Universidad de San Marcos y sus colegios: crónica e investigación., t. I, pp. 17-18.

\section{Anexos Iconográficos}

\section{Imagen I}

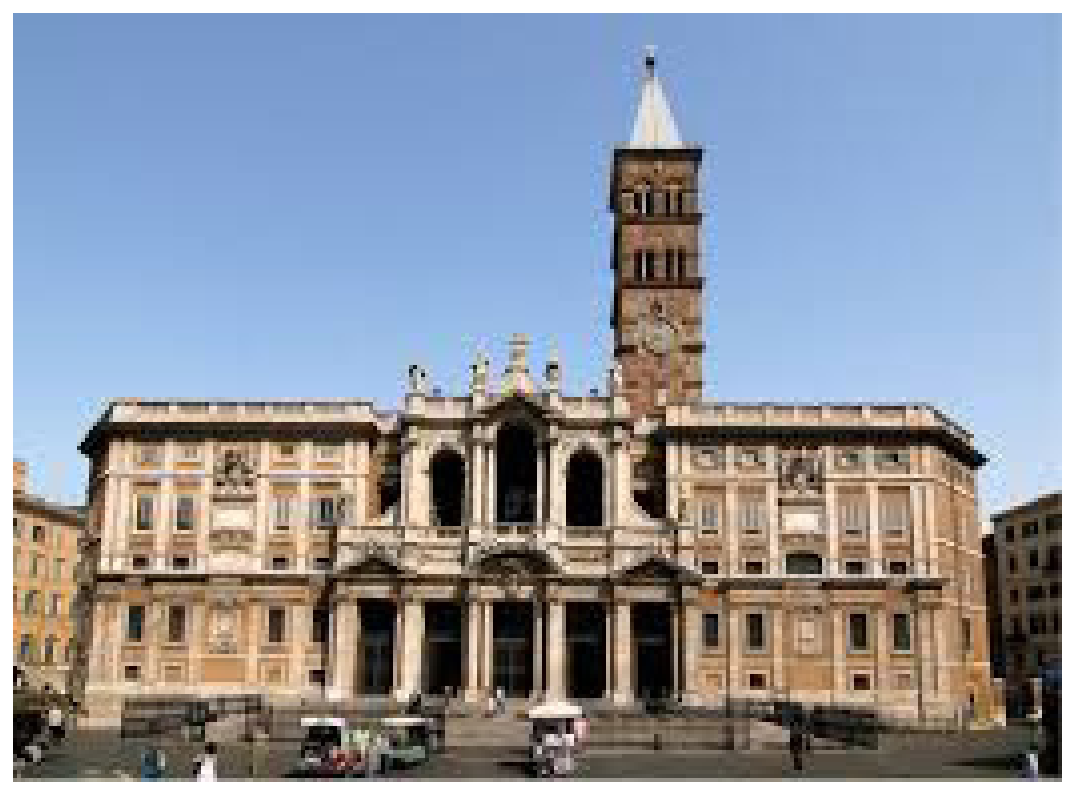

Basílica Santa María la Antigua (exterior) 


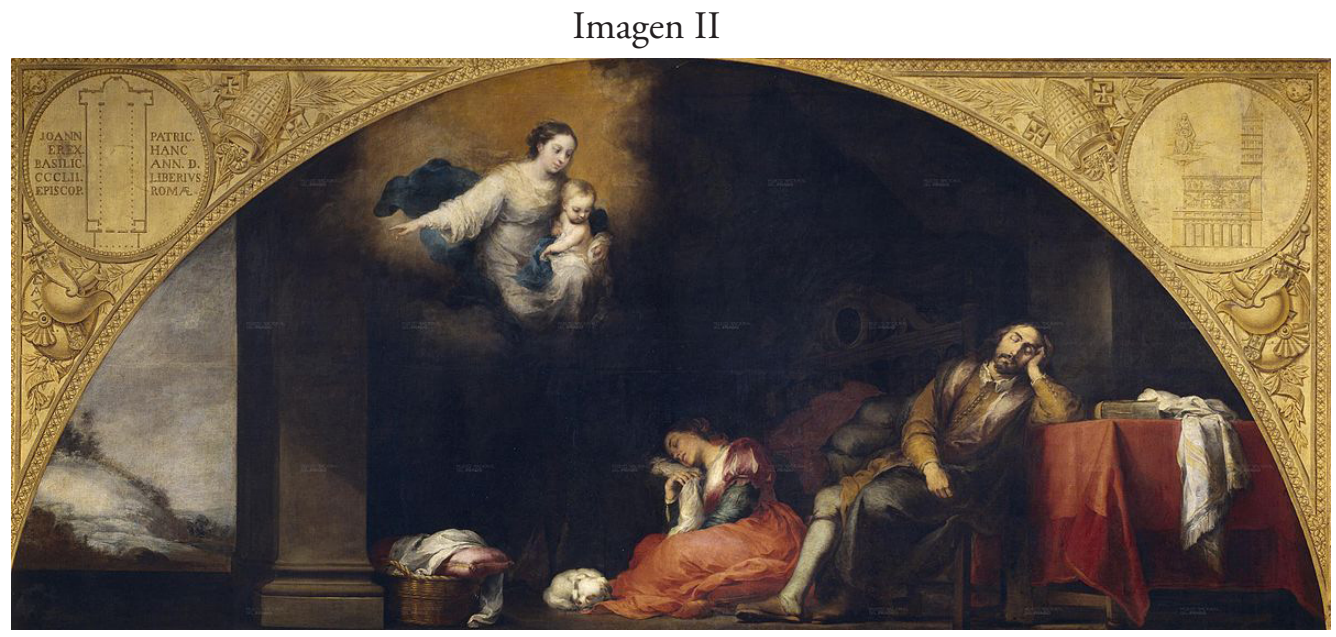

Sueño del patricio Juan

Pintura de Bartolomé Murillo

Imagen III

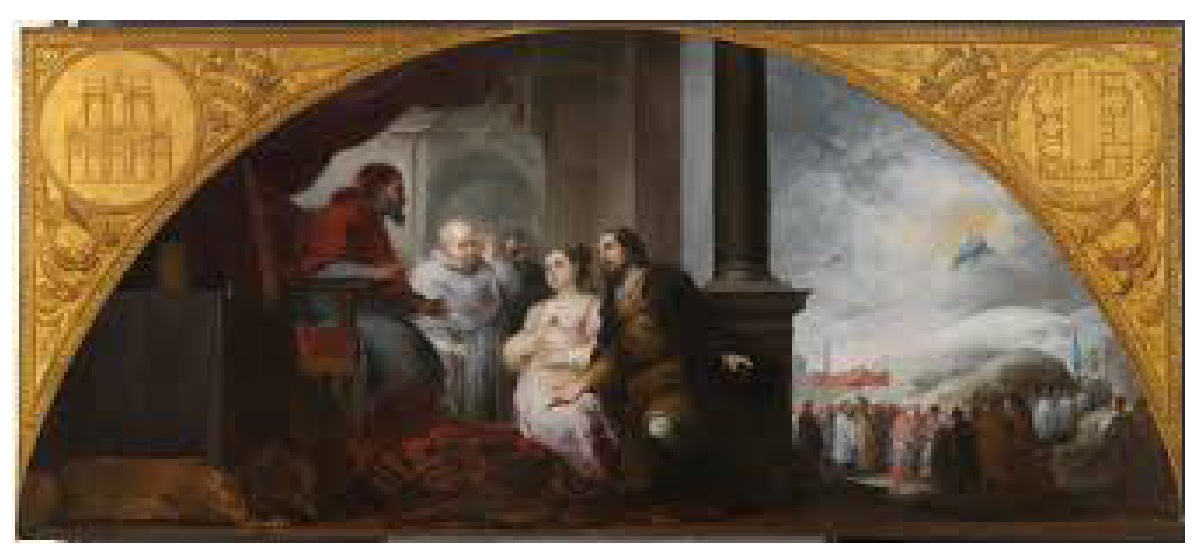

Papa Liberio y patricio Juan con su esposa

Pintura de Bartolomé Murillo 
Imagen IV

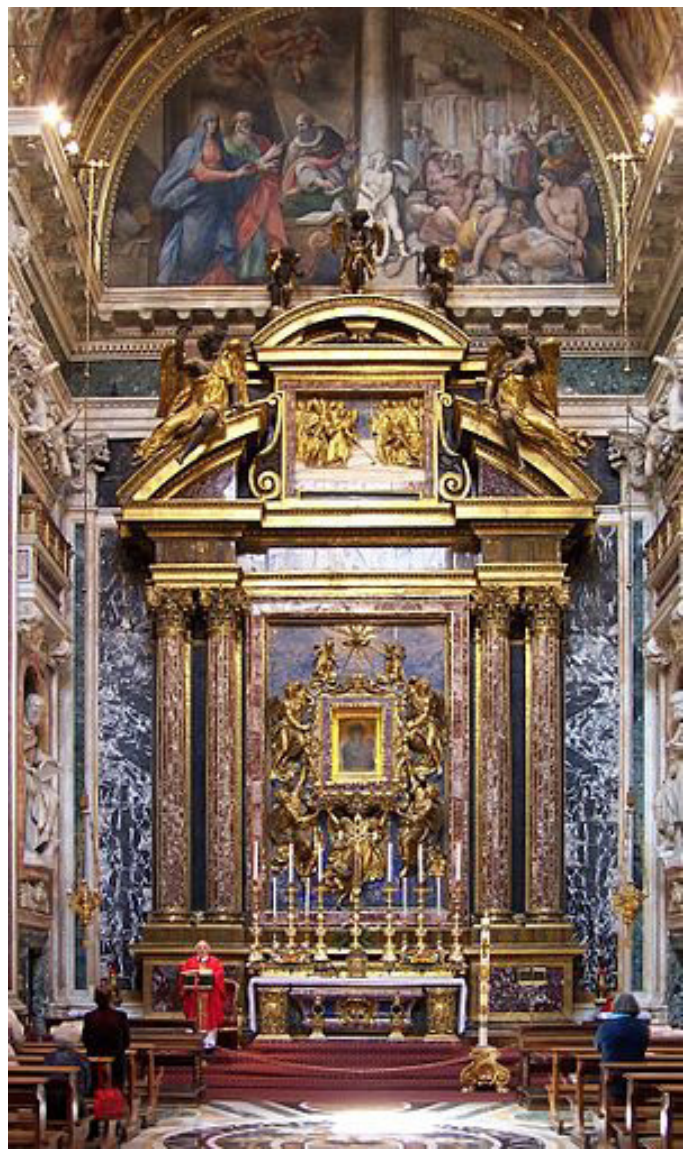

Interior Basílica

Imagen $\mathrm{V}$

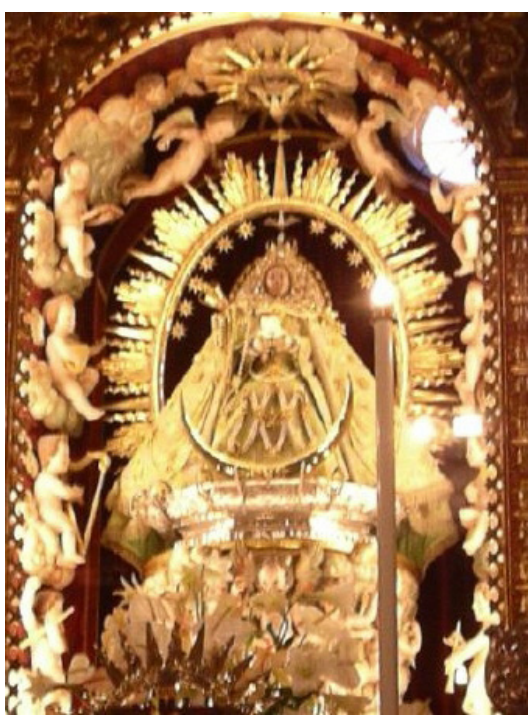

Virgen de las Nieves de La Palma 


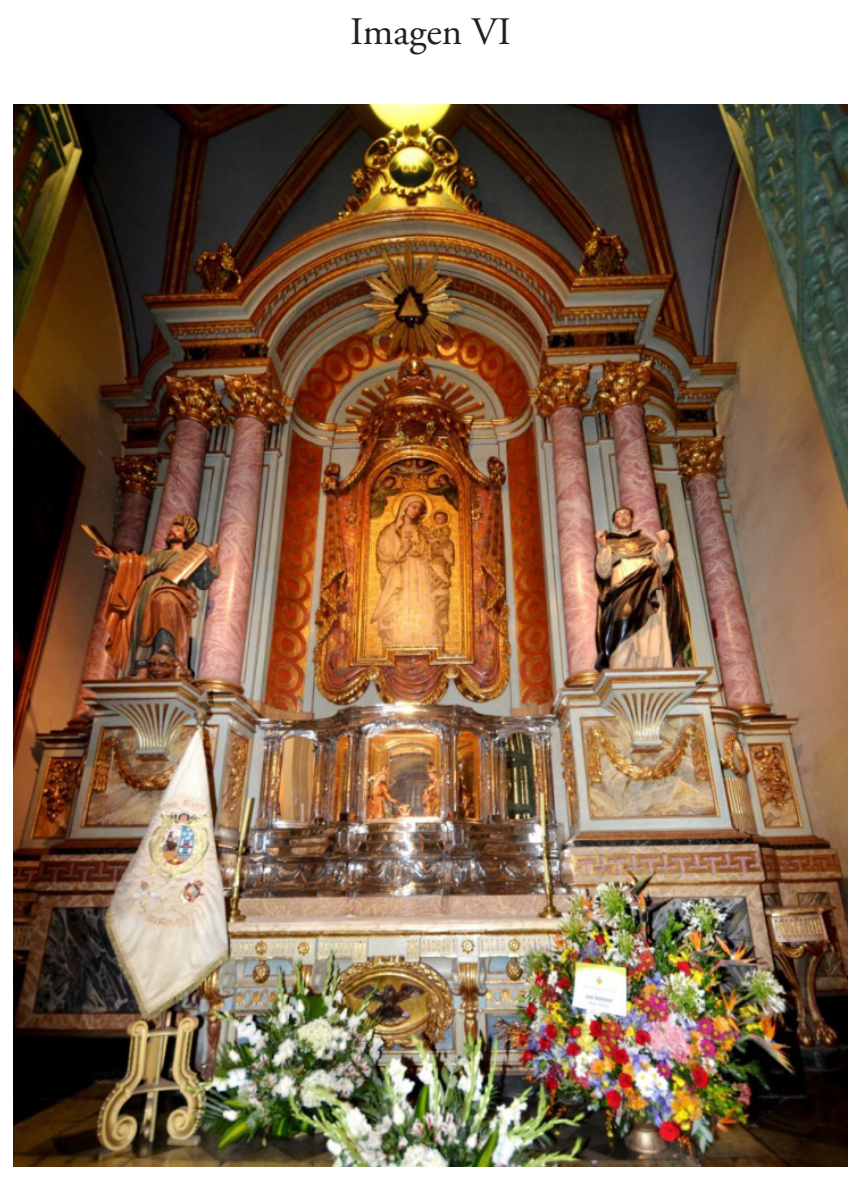

Virgen La Antigua

Imagen VII

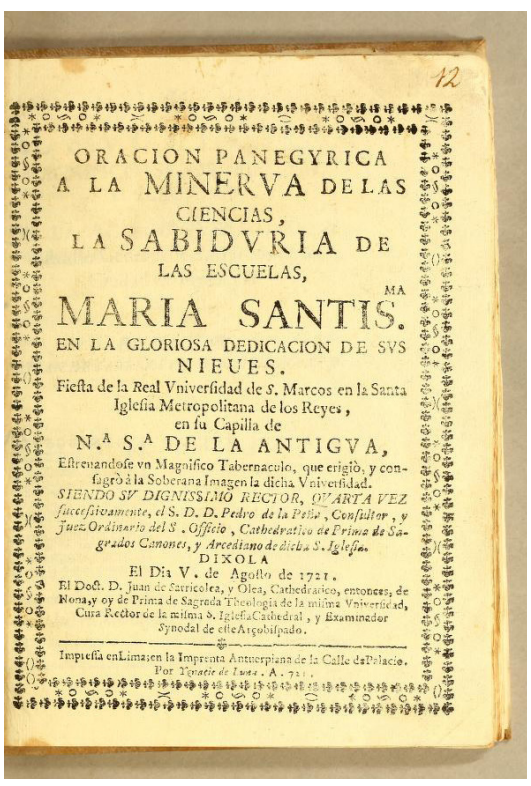

Carátula del Panegírico 
IIIIIIIIII GLORIA CRISTINA FLÓREZ

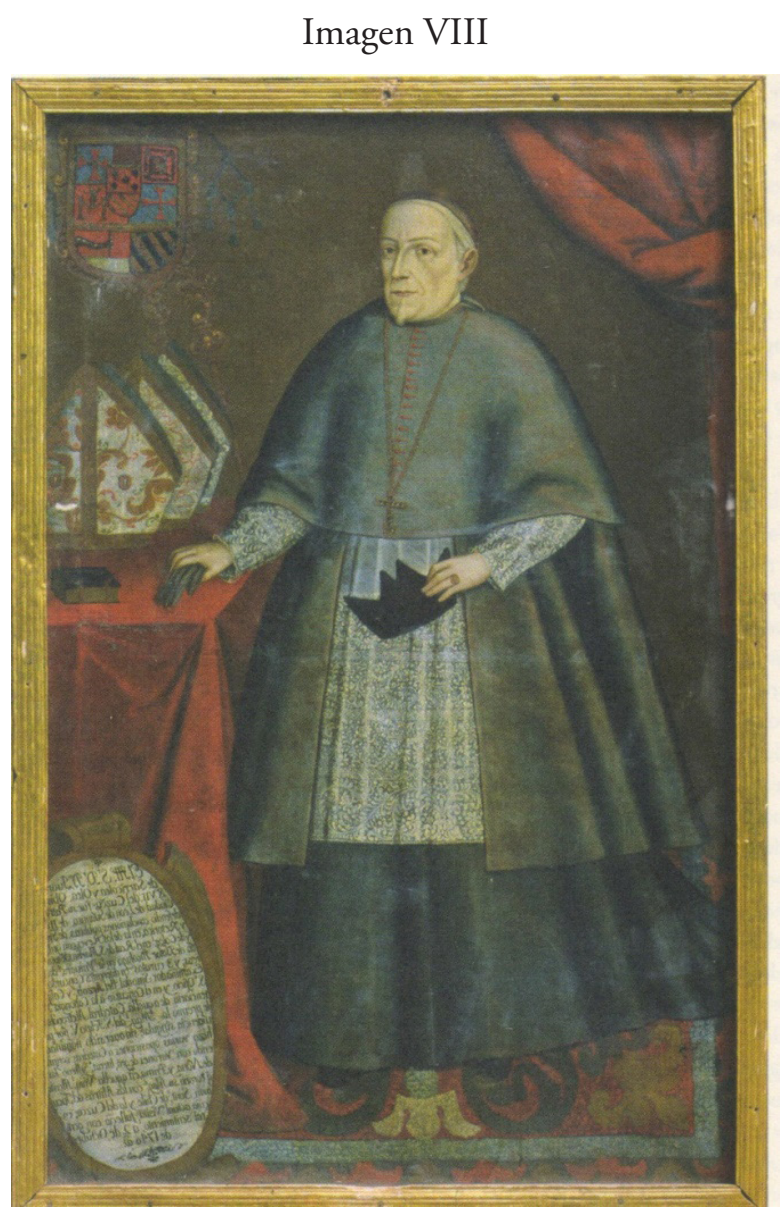

Obispo Juan de Sarricolea 